\title{
Antioxidant and Antimicrobial Properties of Cactus Pear (Opuntia) Seed Oils
}

\author{
Esther Ramírez-Moreno,, Raquel Cariño-Cortés, ${ }^{2}$ Nelly del Socorro Cruz-Cansino, ${ }^{1}$ \\ Luis Delgado-Olivares, ${ }^{1}$ José Alberto Ariza-Ortega, ${ }^{1}$ Vanessa Yelina Montañez-Izquierdo, ${ }^{3}$ \\ María Manuela Hernández-Herrero, ${ }^{3}$ and Tomás Filardo-Kerstupp ${ }^{4}$ \\ ${ }^{1}$ Academic Area of Nutrition, Health Sciences Institute, Autonomous University of Hidalgo State, 42160 Pachuca, HGO, Mexico \\ ${ }^{2}$ Academic Area of Medicine, Autonomous University of Hidalgo State, Eliseo Ramírez Ulloa 400, 42090 Pachuca, HGO, Mexico \\ ${ }^{3}$ Department of Food Hygiene, Faculty of Veterinary, Autonomous University of Barcelona, 08193 Bellaterra, Spain \\ ${ }^{4}$ Academic Area of Chemistry, Basic Science and Engineering Institute, Autonomous University of Hidalgo State, \\ Carretera Pachuca-Tulancingo Km. 4.5, Mineral de la Reforma, 42183 Pachuca, HGO, Mexico
}

Correspondence should be addressed to Nelly del Socorro Cruz-Cansino; ncruz@uaeh.edu.mx

Received 23 January 2017; Accepted 5 April 2017; Published 26 April 2017

Academic Editor: Andrea Lauková

Copyright (c) 2017 Esther Ramírez-Moreno et al. This is an open access article distributed under the Creative Commons Attribution License, which permits unrestricted use, distribution, and reproduction in any medium, provided the original work is properly cited.

\begin{abstract}
Seed oils from two Mexican varieties of cactus pear (green: Opuntia albicarpa and red: Opuntia ficus indica) were extracted with different solvents (hexane, ethanol, and ethyl acetate) to evaluate their antioxidant activity. The seed oil with higher antioxidant activity was selected to evaluate antimicrobial activity. The fatty acid profile was analyzed by gas chromatography-mass spectrometry (GC-MS). Oil from green cactus pear seeds obtained with ethanol and ethyl acetate exhibited higher antioxidant activity $(p<0.05)$ of 323 and $316 \mu \mathrm{mol} \mathrm{TE} / 20 \mathrm{mg}(p<0.05)$, respectively, compared to red cactus pear seed oil $(\approx 274$ and $247 \mu \mathrm{mol} \mathrm{TE} / 20 \mathrm{mg}$ with ethyl acetate and ethanol, resp.). The oil obtained with ethanol and higher antioxidant activity was used to determine the antimicrobial activity. Both cactus pear oils produced a microbial inhibition zone in most of the microorganisms evaluated, particularly Saccharomyces cerevisiae which had similar diameter $(38-40 \mathrm{~mm})$. The oil fatty acids profiles of both varieties were similar and exhibited a high content of linoleic acid, while two fatty acids (linolenic and behenic) found in red cactus pear were not observed in the green variety.
\end{abstract}

\section{Introduction}

A relatively untapped source of lipid and protein raw material is the by-product of fruit-processing plants. Millions of pounds of fruit seeds are discarded yearly causing disposal problems, while proper utilization of these waste products could lead to an important new source of oil and meal [1]. Seeds of fruits collect at least some cytoplasmic lipid bodies as major storage reserve for lipid accumulation [2]. Fruit seeds oils are of great interest because they are edible oils with high degree of unsaturation, antioxidant radical scavenging properties [3-8], and a broad spectrum of antimicrobial activity [9-15]. Therefore, the oil from plants can be potentially used by the food industry for the manufacturing of "natural" or "green" safe foods [16] and extend shelf-life [17, 18].
The oil from cactus pear seed has been found to have an appreciable amount of oil with high levels of unsaturated fatty acids [19], with antioxidant [20,21] and antimicrobial activity [22], as well as cardioprotective, antithrombotic, antiinflammatory, antiarrhythmic, hypolipidemic, and antihyperglycemic effect $[23,24]$. These properties are of interest for the pharmaceutical and food industry. However, the concentration and effectiveness of these oils may vary among cultivars or varieties, crop environmental factors (e.g., light, temperature, and type of soil nutrients), or methods and solvents used for their extraction. Therefore, the purpose of this research was to determine the antioxidant and antimicrobial activity, and fatty acid profile of the oil obtained from two Mexican varieties of cactus pear (Opuntia albicarpa and Opuntia ficus indica) seeds extracted with different solvents. 


\section{Materials and Methods}

2.1. Plant Material. Two Mexican varieties of cactus pear (Opuntia albicarpa and Opuntia ficus indica) fruit, green ( $c v$. Reyna) and red ( $c v$. Rojo Pelón), respectively, were provided by the Mexican association CoMeNTuna (Consejo Mexicano del Nopal y la Tuna, A.C.; Actopan, Hidalgo, Mexico). Fruits free of external injuries were selected, washed, and manually peeled. Cactus pear seeds were obtained after juice was extracted stirring the pulp with an industrial blender (38BL52 LBC10, Waring Comercial ${ }^{\circledR}$, USA) and passing it through a conventional strainer. The seeds retained were washed in the strainer with water until pulp residues were removed.

2.2. Powder Seed and Oil Extraction. Green cactus pear seeds (GCPS) and red cactus pear seeds (RCPS) were sun-dried and then grounded (Cyclotec 1093, Tecator Sweden) to a $1 \mathrm{~mm}$ diameter mesh and stored at $-32^{\circ} \mathrm{C}$ until further analysis. The seed oil was extracted as follows: $25 \mathrm{~g}$ of powdered seeds was mixed with $500 \mathrm{~mL}$ of solvents with varying polarities (hexane, ethanol, and ethyl acetate) and the obtained residue was reextracted until extraction solvents become colourless. All the extracts were filtered through filtration paper Whatman number 1 and the filtered extracts were collected for further drying and removal of the remaining solvent at $50^{\circ} \mathrm{C}$ using a rotary evaporator (BUCHI, R-200, Switzerland). All extracts were placed in plastic bottles and then stored at $-20^{\circ} \mathrm{C}$ until used. The oils obtained were used to further analysis.

2.3. Free Radical Scavenging Assay. The free radical scavenging activity was measured using 1,1-diphenyl-2-picrylhydrazyl $\left(\mathrm{DPPH}^{\circ}\right)$ radical as described by Morales and JiménezPérez [25]. A volume of $500 \mu \mathrm{L}$ of ethanolic $\mathrm{DPPH}^{\bullet}$ solution $(7.4 \mathrm{mg} / 100 \mathrm{~mL})$ was added to a sample aliquot of $100 \mu \mathrm{L}$ placed in vials. The mixture was left to sit at room temperature for $1 \mathrm{~h}$ and then was vortexed and centrifuged at $3000 \mathrm{rpm}$ for 10 minutes. The absorbance of the supernatant was measured at $520 \mathrm{~nm}$ in a microplate reader (Power Wave XS UV-Biotek, software KC Junior, USA), and $\mu \mathrm{mol}$ of Trolox equivalents per 20 milligram ( $\mu \mathrm{mol} \mathrm{TE} / 20 \mathrm{mg}$ ) of sample was obtained. Oil samples with best antioxidant capacity obtained from the different solvents were used for the antimicrobial analysis.

2.4. Antimicrobial Activity. Eight standard freeze-dried cultures of bacteria, Candida albicans (ATCC 10231), Escherichia coli O58:H21 (ATCC 10536), Escherichia coli O157:H7 (CCUG 44857), Staphylococcus aureus (ATCC 13565), Listeria monocytogenes (CCUG 15526), Pseudomonas aeruginosa (ATCC 15442), Saccharomyces cerevisiae (CECT 1942), and Salmonella Typhi (CCUG 29478) were obtained in thermosealed vials from the Spanish Type Culture Collection (Autonomous University of Barcelona, Barcelona, Spain). Freeze-dried cultures were rehydrated in tryptone soy broth at $37^{\circ} \mathrm{C}$ for $18 \mathrm{~h}$ and then were used to inoculate tryptone soy agar and malt extract agar plates; all microorganisms were incubated at $37^{\circ} \mathrm{C}$ except Candida albicans and Saccharomyces cerevisiae which were incubated at $25^{\circ} \mathrm{C}$. Individual colonies were maintained on specific agar slants, stored at $4^{\circ} \mathrm{C}$, and subcultured every 15 days.

Disc Diffusion Assay. Antimicrobial activity of oil extracted from GCPS and RCPS was carried out using the disc diffusion method [26]. Petri plates were filled with $\sim 20 \mathrm{~mL}$ of sterile tryptone soy agar for bacteria and malt extract agar for fungi. The test cultures were swabbed on the top of the solidified media and allowed to dry for 10 minutes. Serial dilutions $(10-50 \mu \mathrm{g} / \mathrm{mL})$ of the seed oil from a stock solution $(1 \mathrm{mg} / \mathrm{mL})$ were prepared in $20 \%$ DMSO and $10 \mu \mathrm{L}$ loaded onto the sterile blank discs $\left(\mathrm{BBL}^{\mathrm{TM}}\right.$ Sensi-Disc $\left.{ }^{\mathrm{TM}}\right)$ of 6 millimeters of diameter. On the media surface the loaded disks were placed and left for 30 minutes at room temperature to allow compound diffusion. The seed oil was serially diluted in Mueller-Hinton broth medium and duplicate tubes of each dilution $(10-100 \mu \mathrm{g} / \mathrm{mL})$ were inoculated with $5 \times$ $10^{6}$ cells of the test bacteria strain and cultures. The antibiotic agents Sensi-Disc streptomycin, ampicillin, and sulfamethoxazole/trimethoprim (BBL Sensi-Disc) were used as positive controls at the same concentration level. After plates were incubated at $37^{\circ} \mathrm{C}$ for $24 \mathrm{~h}$, the diameters of the inhibition zones were recorded in millimeters. Three independent repetitions were performed and tests were made in triplicate.

2.5. GC-MS Analysis. The GC-MS analysis was performed with a GC-MS HP-5890 (Hewlett-Packard Company, Palo Alto, California, USA) equipped with a Flame Ionization Detector (FID), and a ZB-WAX fused silica capillary column $(60 \mathrm{~m} \times 0.25 \mathrm{~mm}$ i.d. $\times 0.25 \mathrm{~mm}$ film thickness $)$ packed with $5 \%$ phenylmethylpolysiloxane (Phenomenex, Torrance, CA). To obtain the methyl esters, the cactus pear seed oils were saponified and derivatized using $\mathrm{KOH} 1 \mathrm{~N}$ (IUPAC, 1969). Changes in the fatty acids of the oils samples were compared against a standard mixture of 37 components of fatty acids methyl esters (FAMEs) (Food Industry FAMEs Mix, Restek) comprised by methyl esters with chains C4:0, C6:0, C8:0, C10:0, C11:0, C12:0, C13:0, C14:0, C14:1, C15:0, C15:1, C16:0, C16:1, C17:0, C17:1, C18:0, C18:1n9c, C18:1n9t, C18:2n6c, C18:2n6t, C18:3n6, C18:3n3, C20:0, C20:1n9, C20:2, C20:3n6, C20:3n3, C20:4n6, C20:5n3, C21:0, C22:0, C22:1n9, C22:2, C22:6n3, C23:0, C24:0, and C24:1n9. The sample volume injected was of $2 \mu \mathrm{L}$ (split ratio $20: 2$ ) at an injector and detector temperatures of 225 and $225^{\circ} \mathrm{C}$, respectively. $\mathrm{N}_{2}$ was used as carrier gas at a flow rate of $1.2 \mathrm{~mL} \cdot \mathrm{min}^{-1}$. Fatty acids were calculated as percentage of total FAMEs.

2.6. Statistical Analysis. All values were obtained by triplicate and expressed as means \pm standard deviations (SD). Data were analyzed using the SPSS V.15 software (SPSS Institute Inc., Cary, NC). An ANOVA was carried out to determine differences between oils extracted as well as its antimicrobial activity that were significant at the $5 \%$ level of probability and a Tukey test was used for comparison of data.

\section{Results and Discussion}

3.1. Yield Comparison between Extraction Solvents. Hexane, ethanol, and ethyl acetate were used to extract the oil from 


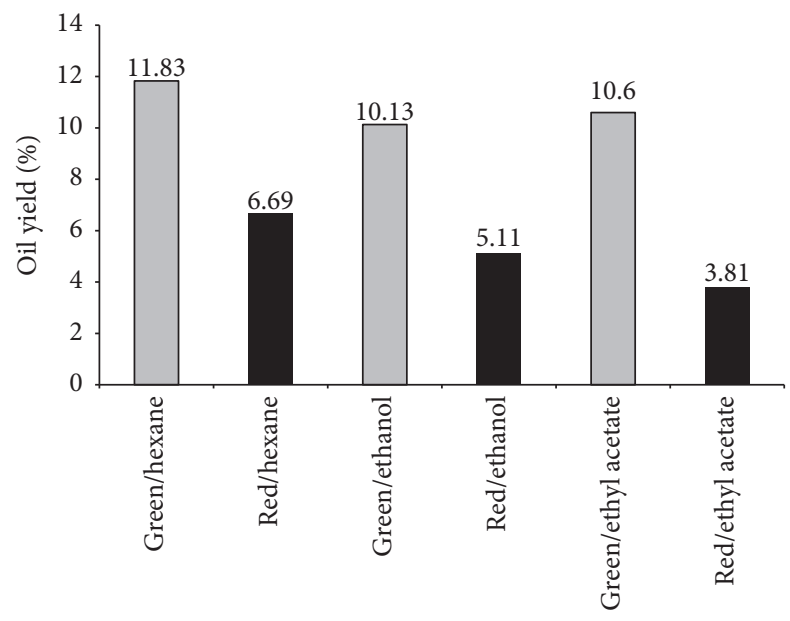

Figure 1: Oil yields (\%) extracted from GCPS and RCPS with hexane, ethanol, and ethyl acetate.

cactus pear seeds. The extraction yields are compared in Figure 1, which shows that the higher amount of oil (\%) was obtained from the green cultivar and that yield depended on the solvent used. Oil extraction with hexane was higher for both fruit varieties (11.83\% for GCPS and 6.89\% for RCPS), followed by ethanol, which reached the same yield as ethyl acetate for GCPS $(\approx 10 \%)$. Ethyl acetate was the least effective solvent for RCPS. The extraction yields were similar to those reported $(\approx 7$ to $11 \%$ ) for several varieties of Opuntia ficus indica [27-29]. This extraction yields will vary depending on several factors as fruit variety, harvest period, maturation, geographic region, percentage of oil in the seed, and chemical compounds found in the source and by the extraction method [30]. Researchers have determined that solvent extraction combined with other methods could increase oil yield, as high pressure or supercritical fluid combined with solvent reached a yield of $9.33 \%$ from tobacco seeds (Nicotiana tabacum L.) while sonication and Soxhlet reached a $7.75 \%$ and $13.72 \%$, respectively [31].

3.2. Free Radical Scavenging Activity. Solvent extraction is usually used for isolation of antioxidants; the extraction depends on the solvent selected based on the different antioxidant compounds with varying polarity $[32,33] . \mathrm{DPPH}$ is a stable free radical that accepts an electron or hydrogen radical to become a stable diamagnetic molecule $[34,35]$. The DPPH assay has also been used to predict the oxidative stability of edible oils $[36,37]$. The antioxidant activity determined by DPPH of the oil extracted from RCPS and GCPS is shown in Figure 2. Oil from the GCPS extracted with ethanol and ethyl acetate exhibited the higher antioxidant activity $(p<$ 0.05 ) of 323 and $316 \mu \mathrm{mol} \mathrm{TE} / 20 \mathrm{mg}$ extract, respectively, followed by RCPS oil extracted with ethyl acetate $(274 \mu \mathrm{mol}$ TE/20 mg extract) and ethanol ( $247 \mu \mathrm{mol} \mathrm{TE} / 20 \mathrm{mg}$ extract $)$. These results demonstrate that the extraction solvent had a significant effect on the free radical scavenging capacity of the oil, where the hexane had the lower values. In our study, the green variety exhibited a higher antioxidant activity regardless of solvent. Different results may depend mainly

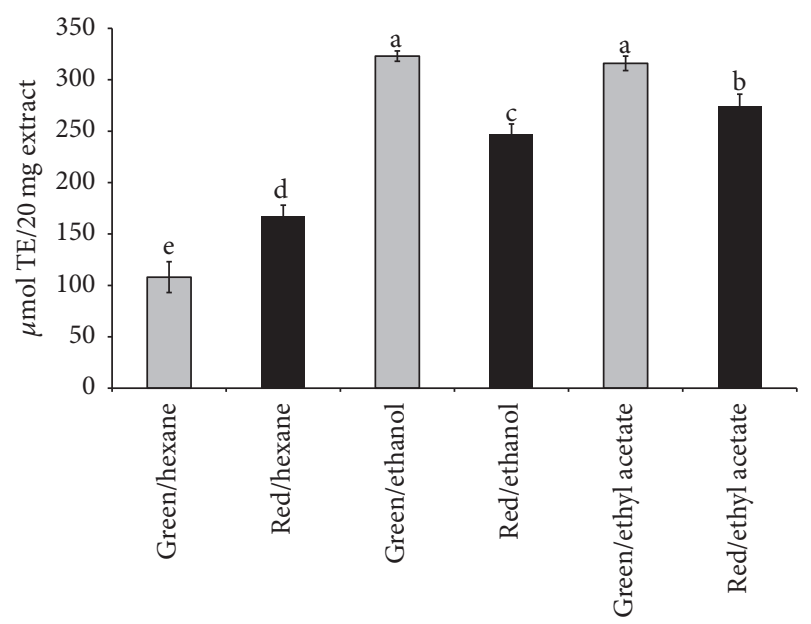

FIGURE 2: Antioxidant activity of GCPS and RCPS oils extracted with different solvents. ${ }^{\mathrm{a}-\mathrm{d}}$ Different letters above bars indicate that samples are significantly different $(p<0.05)$.

on the content and concentration of bioactive compounds in the oil, but other factors such as solvent polarity, solubility of the extracts in different testing systems, stereoselectivity of the radicals [38], and strong synergism between fatty acids [6] may affect antioxidant activities. Other studies have also reported diverse antioxidant activity among oils from different Opuntia varieties [20, 39, 40].

3.3. Antibacterial and Antifungal Activity. The most recommended way to prevent or inhibit microbial growth in foods is the use of food preservatives. Essential oils are secondary metabolites of plants that have wide applications in the food flavoring and preservative industry [41]. Six different bacterium and two fungi species were used to screen the antimicrobial potential of the oils extracted from the two varieties of cactus pear seeds. Oil extracted with ethanol exhibited the highest antioxidant activity and therefore it was used to evaluate the antibacterial and antifungal activity. Figure 3 shows the results from the microbial assay where most microorganisms showed an inhibition zone when exposed to GCPS and RCPS oils, except Salmonella Typhi and Escherichia coli O157:H7 (image not shown). From these two microorganisms, the first showed an inhibition zone in the presence of antibiotic agents streptomycin (S), ampicillin (AMP), and sulfamethoxazole/trimethoprim (STX) in diameters of $14.6,11.3$ and $27.3 \mathrm{~mm}$, respectively (Table 1), while Escherichia coli O157:H7 was only inhibited by SXT $(25.3 \mathrm{~mm})$, which agrees with other reports of multiantibiotic resistance of E. coli O157:H7 due to the presence of the gene cluster AMR-SSuT [42] and production of betalactamase [43]. On the other hand, Saccharomyces cerevisiae was highly inhibited $(38-40 \mathrm{~mm})$ by the extracted oils but grew in presence of the antimicrobial agents (Figure 3). Similar results were observed for Candida albicans, although inhibition zones were smaller and similar for both oils. These observations demonstrate that certain compounds in the cactus pear seed oil have antimicrobial activity. Other researchers also reported similar observations for cactus 
TABLE 1: Diameters of growth inhibition zones $(\mathrm{mm})$ in the presence of oil extracted from cactus pear seeds and conventional antimicrobials ${ }^{\mathrm{A}}$.

\begin{tabular}{|c|c|c|c|c|c|}
\hline \multirow{2}{*}{ Microbial cultures } & \multicolumn{2}{|c|}{ Extract } & \multicolumn{3}{|c|}{ Antimicrobial agent } \\
\hline & GCPS & RCPS & $S$ & AMP & SXT \\
\hline Saccharomyces cerevisiae (CECT1942) & $38.3 \pm 4.2^{\mathrm{a}}$ & $40.3 \pm 4.5^{\mathrm{a}}$ & ND & ND & ND \\
\hline Escherichia coli O58:H21 (ATCC 10536) & $11.9 \pm 0.7^{\mathrm{d}}$ & $11.4 \pm 0.9^{\mathrm{d}}$ & $19.5 \pm 1.4^{\mathrm{b}}$ & $17.8 \pm 1.5^{\mathrm{c}}$ & $29.9 \pm 0.9^{\mathrm{a}}$ \\
\hline Escherichia coli O157:H7 (CCUG 44857) & $\mathrm{ND}^{\mathrm{B}}$ & ND & ND & ND & $25.3 \pm 1.0$ \\
\hline Staphylococcus aureus (ATCC 13565) & $12.1 \pm 1.0^{\mathrm{c}}$ & $11.1 \pm 1.1^{\mathrm{c}}$ & $18.3 \pm 0.9^{b}$ & $28.1 \pm 1.5^{\mathrm{a}}$ & $33.3 \pm 1.9^{\mathrm{a}}$ \\
\hline Listeria monocytogenes (CCUG15526) & $13.3 \pm 1.5^{\mathrm{c}}$ & $11.4 \pm 0.9^{\mathrm{d}}$ & $21.3 \pm 1.2^{\mathrm{a}}$ & $17.3 \pm 0.8^{c}$ & $37.6 \pm 1.8^{\mathrm{a}}$ \\
\hline Pseudomonas aeruginosa (ATCC15442) & $16.4 \pm 2.1^{\mathrm{c}}$ & $15.1 \pm 2.0^{\mathrm{c}}$ & $20.1 \pm 1.5^{\mathrm{b}}$ & $24.1 \pm 2.5^{\mathrm{a}}$ & $36.6 \pm 2.9^{\mathrm{a}}$ \\
\hline Salmonella typhi (CCUG29478) & ND & ND & $14.6 \pm 0.4^{\mathrm{b}}$ & $11.3 \pm 1.8^{\mathrm{c}}$ & $27.3 \pm 0.8^{\mathrm{a}}$ \\
\hline Candida albicans (ATCC 10231) & $11.1 \pm 1.0^{\mathrm{a}}$ & $11.0 \pm 1.8^{\mathrm{a}}$ & ND & ND & ND \\
\hline
\end{tabular}

${ }^{\mathrm{A}}$ Inhibition zone diameters for oil and reference antibiotics are means \pm SE of three replicas. GCPS: green cactus pear seed oil extract, RCPS: red cactus pear seed oil extract, S: streptomycin (10 $\mu \mathrm{g} / \mathrm{disc})$, AMP: ampicillin $(10 \mu \mathrm{g} / \mathrm{disc})$, and SXT: sulfamethoxazole/trimethoprim $(10 \mu \mathrm{g} /$ disc $) .{ }^{\mathrm{B}} \mathrm{ND}$ : not detected activity. ${ }^{\mathrm{a}-\mathrm{d}}$ Different letters in the same row indicate significant differences.

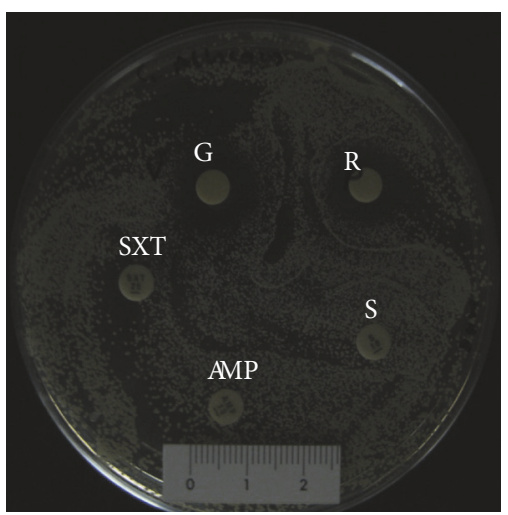

(a)

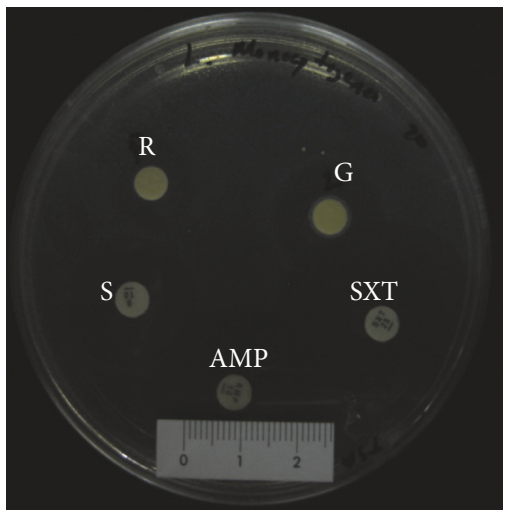

(d)

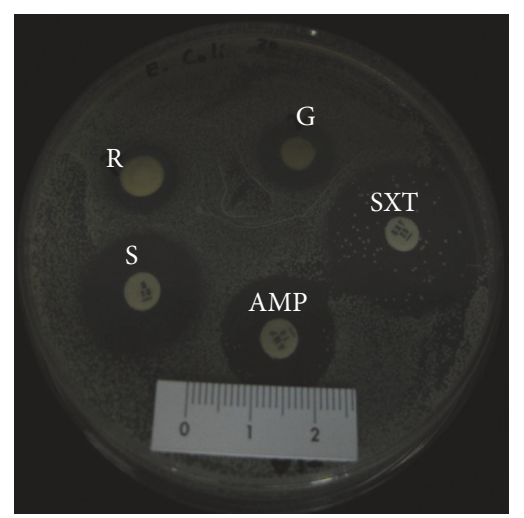

(b)

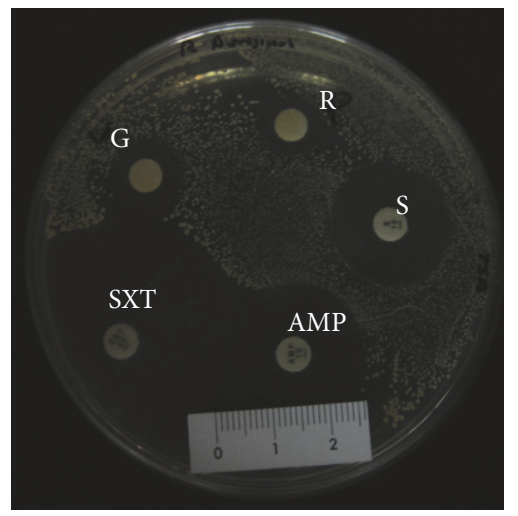

(e)

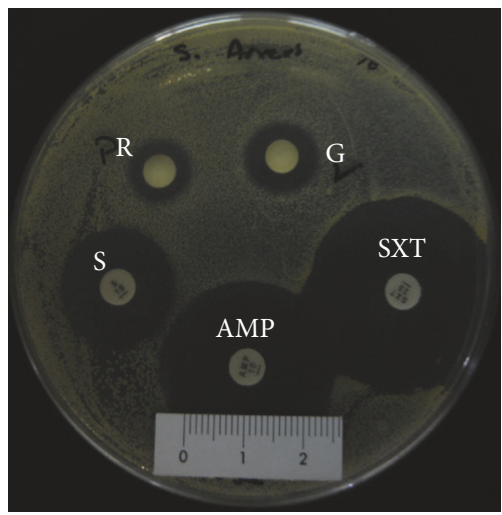

(c)

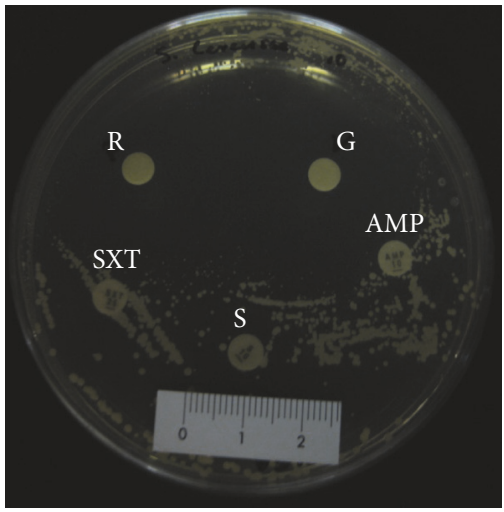

(f)

FIGURE 3: Antimicrobial activity of oil extracted from green cactus pear (G); oil extracted from red cactus pear seeds (R); streptomycin (S); ampicillin (AMP); and sulfamethoxazole/trimethoprim (SXT). Candida. albicans (ATCC 10231) (a); Escherichia. coli O58:H21 (ATCC 10536) (b); Staphylococcus aureus (ATCC 13565) (c); Listeria monocytogenes (CCUG15526) (d); Pseudomonas aeruginosa (ATCC15442) (e); Saccharomyces cerevisiae (CECT1942) (f).

pear fruit cv. Opuntia stricta [44] and for other plants as fennel (Foeniculum vulgare L.) and chamomile (Matricaria chamomilla L.) [5]. Differences in the levels of antimicrobial activity may be partially attributed to variable chemical composition of the oils [45]. Mnayer et al. [46] suggested that oil compounds can act on different bacterial structures, while Gill et al. [47] mentioned that whole oils have a greater antibacterial activity than the major component mixed, so that minor components are critical for the activity and exert a synergistic effect $[16,48,49]$.

In the present study, the antimicrobial activity of cactus pear seed oil was more effective against fungi compared to bacteria cultures. These interesting results suggest that there is a link between the oil chemical contents and the 
TABLE 2: Percentages of FAMEs in crude cactus pear seed oil extracts.

\begin{tabular}{lcc}
\hline FAMEs & Green cactus pear seed oil extract & Red cactus pear seed oil extract \\
\hline C14:0 & $0.078 \pm 0.00$ & $0.066 \pm 0.01$ \\
C16:0 & $12.327 \pm 0.09$ & $12.887 \pm 0.02$ \\
C16:1 & $0.429 \pm 0.02$ & $0.570 \pm 0.01$ \\
C16:2 & $0.073 \pm 0.00$ & $0.540 \pm 0.00$ \\
C17:0 & $0.060 \pm 0.01$ & $0.075 \pm 0.00$ \\
C18:0 & $3.436 \pm 0.01$ & $3.389 \pm 0.07$ \\
C18:1 & $16.215 \pm 0.03$ & $17.061 \pm 0.01$ \\
C18:2 & $67.448 \pm 0.08$ & $65.407 \pm 0.01$ \\
C18:3 & $\mathrm{Ni}$ & $0.372 \pm 0.01$ \\
C22:0 & $\mathrm{Ni}$ & $0.160 \pm 0.01$ \\
\hline
\end{tabular}

Means of 3 replicates \pm SE. Ni: not identified.

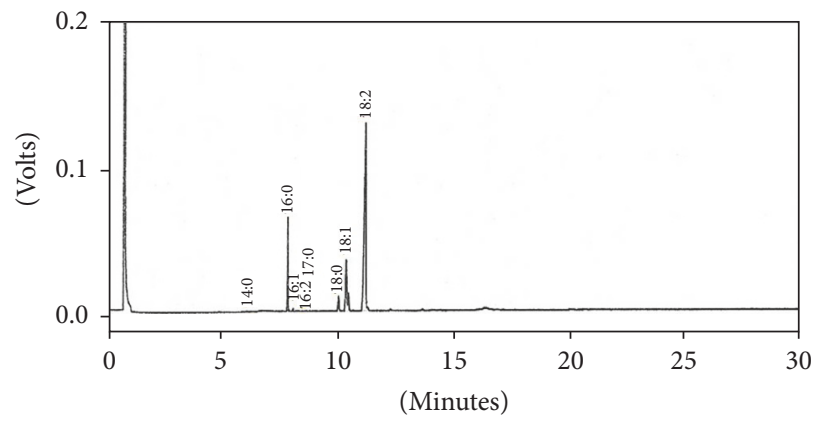

(a)

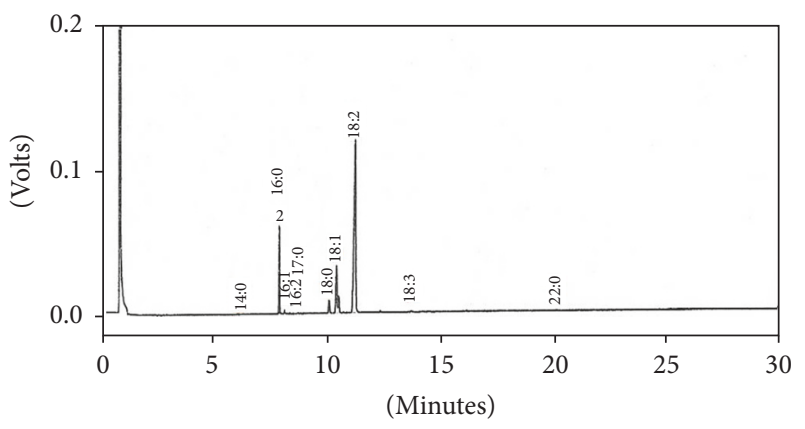

(b)

FIGURE 4: Chromatograms of FAMEs of cactus pear seed oil extract. (a) Green cactus pear seed oil extract; (b) red cactus pear seed oil extract. In both oils extracts were identified: myristic (C14:0), palmitic (C16:0), palmitoleic (C16:1, cis-9), hexadecadienoic (C16:2, cis-9, 12), margaric (C17:0), stearic (C18:0), oleic (C18:1, cis-9), linoleic (C18:2, cis-9, 12), except linolenic (C18:3, cis-6, 9, 12), and behenic (C22:0) fatty acids that were identified only in red cactus pear seed.

antimicrobial activity. The membrane disruption could be one mechanism of action by inactivating microbial adhesion, enzymes, and proteins transport $[15,46]$. RCPS and GCPS extracts inhibited most of the evaluated bacterial and fungi species (Table 1); however, antimicrobial activity was not detected for Salmonella Typhi, which is a gram-negative bacterium. In general, gram-negative bacteria have an effective outer membrane that restricts the penetration of amphipathic compounds and has a mechanism to extrude toxins across [50]. This may explain the apparent antimicrobial ineffectiveness of the oils against the permeability barrier in addition to the presence of multidrug resistance encoding plasmids [51].

3.4. Fatty Acid Profile. FAMEs chromatograms and percentages are shown in Figure 4 and Table 2. Cactus pear seed oils contained saturated and unsaturated fatty acids, the linoleic fatty acid being the predominant $(67.4 \%$ and $65.4 \%$ in GCPS and RCPS oils, resp.). Minimal amounts of myristic (C14:0), palmitoleic (C16:1), hexadecadienoic (C16:2), and margaric (C17:0) fatty acids in both oils were also identified. The fatty acids profiles of the two cactus pear varieties were similar; however the GCPS had a slightly higher content of the linoleic acid (C18:2) while the fatty acids linolenic (C18:3) and behenic (C22:0) were in minimal amounts only in the RCPS.
Different studies have established that factors as cultivar type, temperature, and harvest time have a strong influence in parameter as $\mathrm{pH}$, Brix, vitamin $\mathrm{C}$, sugars, and fat content [52, 53]. Oumato et al. [52] found differences in linoleic fatty acid (C18:2) content among cactus pear cultivars. In other study, the oleic acid (C18:1) content was significantly influenced by the cultivar and location interaction [53], providing unique characteristics to the oil.

In comparison with other plants oils, the linoleic acid (C18:2) content of the cactus pear fruit was similar to the levels reported for sunflower oil (62\%) [54] and higher than wheat germ oil (55.05\%) [55] and soybean oil (52.70\%) [56]. The contents of other FAMEs in cactus pear varieties such as palmitic (C16:0), oleic (C18:1), and stearic (C18:0) were similar to those reported for Castilla blackberry (Rubus glaucus Benth) with 11.24\%, passion fruit (Passiflora edulis) with $15.47 \%$ [57], and grape (Vitis vinifera) with 3.5\% [58].

Other researchers have reported similar fatty acids profile to our findings for different plant materials and have analyzed the antimicrobial effectiveness against different microorganisms. For instance, fatty acids found in Allium cepa were found to effectively inhibit Staphylococcus aureus, Bacillus subtilis, Enterococcus faecalis, Escherichia coli, and Klebsiella pneumoniae [59]. Oil extracted from Swietenia Macrophylla king seed oil inhibited growth of S. aureus, 
S. Typhimurium, and $P$ aeruginosa [60]. These studies demonstrate that seed oil can inhibit fungi and bacteria, but their efficacy would depend on their concentration levels and specific pathogen [15].

\section{Conclusions}

Oil yield from the green cactus pear was higher in comparison to the red cultivar and was also influenced by the solvent used. Hexane exhibited high extraction yield while oils extracted with ethanol had the better antioxidant activity. The results demonstrated that oil extracts from both varieties have a noticeable antimicrobial activity against gram-positive and gram-negative bacteria comparable to antimicrobial compounds such as ampicillin, streptomycin, and sulfamethoxazole/trimethoprim. This research provides further incentives to develop additives for the food, cosmetic, and pharmaceutical sectors seeking natural compounds with antimicrobial activity. Further studies are needed to determine the specific component responsible for the antimicrobial activity in cactus pear seeds oil and determine the optimum levels of oil extract and the antimicrobial effectiveness in the food matrix.

\section{Additional Points}

Practical Application. Our results suggest that the oils extracted from cactus pear seeds have the potential to be used as a natural antioxidant and antimicrobial agents by the food, cosmetic, and pharmaceutical sectors.

\section{Conflicts of Interest}

The authors have declared that no conflicts of interest exist.

\section{Acknowledgments}

This study was possible thanks to the financial support from the Programa Integral de Fortalecimiento Institucional (PIFI 2013-2015), Mexico. This research project was partially supported by the Food Hygiene Department, Faculty of Veterinary from the Autonomous University of Barcelona, Spain. The authors acknowledge the Mexican association CoMeNTuna (Consejo Mexicano del Nopal y la Tuna, Hidalgo, Mexico) for providing the plant materials.

\section{References}

[1] B. S. Kamel and Y. Kakuda, "Fatty acids in fruits and fruit products," in Acids in Foods and Their Health Implications, pp. 263301, CRC Press, 3rd edition, 2007.

[2] D. J. Murphy, I. Hernández-Pinzón, and K. Patel, "Role of lipid bodies and lipid-body proteins in seeds and other tissues," Journal of Plant Physiology, vol. 158, no. 4, pp. 471-478, 2001.

[3] A. Kedia, B. Prakash, P. K. Mishra, and N. K. Dubey, "Antifungal and antiaflatoxigenic properties of Cuminum cyminum (L.) seed essential oil and its efficacy as a preservative in stored commodities," International Journal of Food Microbiology, vol. 168-169, pp. 1-7, 2014.
[4] S. Singh, S. S. Das, G. Singh, C. Schuff, M. P. de Lampasona, and C. A. Catalán, "Composition, in vitro antioxidant and antimicrobial activities of essential oil and oleoresins obtained from black cumin seeds (Nigella sativa L.).," BioMed Research International, vol. 2014, Article ID 918209, 10 pages, 2014.

[5] M. H. H. Roby, M. A. Sarhan, K. A.-H. Selim, and K. I. Khalel, "Antioxidant and antimicrobial activities of essential oil and extracts of fennel (Foeniculum vulgare L.) and chamomile (Matricaria chamomilla L.)," Industrial Crops and Products, vol. 44, pp. 437-445, 2013.

[6] G. Kavoosi, A. Tafsiry, A. A. Ebdam, and V. Rowshan, "Evaluation of antioxidant and antimicrobial activities of essential oils from carum copticum seed and ferula assafoetida latex," Journal of Food Science, vol. 78, no. 2, pp. T356-T361, 2013.

[7] S. Lalas, O. Gortzi, V. Athanasiadis, J. Tsaknis, and I. Chinou, "Determination of antimicrobial activity and resistance to oxidation of Moringa peregrina seed oil," Molecules, vol. 17, no. 3, pp. 2330-2334, 2012.

[8] B. Ozcan, M. Esen, M. K. Sangun, A. Coleri, and M. Caliskan, "Effective antibacterial and antioxidant properties of methanolic extract of Laurus nobilis seed oil," Journal of Environmental Biology, vol. 31, no. 5, pp. 637-641, 2010.

[9] R. S. Bhat and S. Al-daihan, "Antimicrobial activity of Litchi chinensis and Nephelium lappaceum aqueous seed extracts against some pathogenic bacterial strains," Journal of King Saud University-Science, vol. 26, no. 1, pp. 79-82, 2014.

[10] J. M. Silván, E. Mingo, M. Hidalgo, S. de Pascual-Teresa, A. V. Carrascosa, and A. J. Martinez-Rodriguez, "Antibacterial activity of a grape seed extract and its fractions against Campylobacter spp.," Food Control, vol. 29, no. 1, pp. 25-31, 2013.

[11] K. Rakholiya, M. Kaneria, D. Desai, and S. Chanda, "Antimicrobial activity of decoction extracts of residual parts (seed and peels) of Mangifera indica L. var. Kesar against pathogenic and food spoilage microorganism," in Microbial pathogens and strategies for combating them: science, technology and education, A. Méndez-Vilas, Ed., vol. 2, pp. 850-856, 2013.

[12] N. A. Hasan, M. Z. Nawahwi, and H. Ab Malek, "Antimicrobial activity of Nigella sativa seed extract," Sains Malaysiana, vol. 42, no. 2, pp. 143-147, 2013.

[13] Z. I. Sajid, F. Anwar, G. Shabir, G. Rasul, K. M. Alkharfy, and A.H. Gilani, "Antioxidant, antimicrobial properties and phenolics of different solvent extracts from bark, leaves and seeds of Pongamia pinnata (L.) pierre," Molecules, vol. 17, no. 4, pp. 39173932, 2012.

[14] M. Khoobchandani, B. K. Ojeswi, N. Ganesh et al., "Antimicrobial properties and analytical profile of traditional Eruca sativa seed oil: comparison with various aerial and root plant extracts," Food Chemistry, vol. 120, no. 1, pp. 217-224, 2010.

[15] V. Kesari, A. Das, and L. Rangan, "Physico-chemical characterization and antimicrobial activity from seed oil of Pongamia pinnata, a potential biofuel crop," Biomass and Bioenergy, vol. 34, no. 1, pp. 108-115, 2010.

[16] K. Carović-Stanko, S. Orlić, O. Politeo et al., "Composition and antibacterial activities of essential oils of seven Ocimum taxa," Food Chemistry, vol. 119, no. 1, pp. 196-201, 2010.

[17] M. M. Tajkarimi, S. A. Ibrahim, and D. O. Cliver, "Antimicrobial herb and spice compounds in food," Food Control, vol. 21, no. 9, pp. 1199-1218, 2010.

[18] F. Solórzano-Santos and M. G. Miranda-Novales, "Essential oils from aromatic herbs as antimicrobial agents," Current Opinion in Biotechnology, vol. 23, no. 2, pp. 136-141, 2012. 
[19] N. Chougui, A. Tamendjari, W. Hamidj et al., "Oil composition and characterisation of phenolic compounds of Opuntia ficusindica seeds," Food Chemistry, vol. 139, no. 1-4, pp. 796-803, 2013.

[20] W. Liu, Y.-J. Fu, Y.-G. Zu et al., "Supercritical carbon dioxide extraction of seed oil from Opuntia dillenii Haw. and its antioxidant activity," Food Chemistry, vol. 114, no. 1, pp. 334-339, 2009.

[21] B. Matthäus and M. M. Özcan, "Habitat effects on yield, fatty acid composition and tocopherol contents of prickly pear (Opuntia ficus-indica L.) seed oils," Scientia Horticulturae, vol. 131, pp. 95-98, 2011.

[22] P. Zito, M. Sajeva, M. Bruno, S. Rosselli, A. Maggio, and F. Senatore, "Essential oils composition of two Sicilian cultivars of Opuntia ficus-indica (L.) Mill. (Cactaceae) fruits (prickly pear)," Natural Product Research, vol. 27, no. 14, pp. 1305-1314, 2013.

[23] K. Mobraten, T. M. Haug, C. R. Kleiveland, and T. Lea, "Omega3 and omega-6 PUFAs induce the same GPR120-mediated signalling events, but with different kinetics and intensity in Caco-2 cells," Lipids in Health and Disease, vol. 12, no. 1, Article ID 101, 2013.

[24] A. Berraaouan, A. Ziyyat, H. Mekhfi et al., "Evaluation of antidiabetic properties of cactus pear seed oil in rats," Pharmaceutical Biology, vol. 52, no. 10, pp. 1286-1290, 2014.

[25] F. J. Morales and S. Jiménez-Pérez, "Free radical scavenging capacity of Maillard reaction products as related to colour and fluorescence," Food Chemistry, vol. 72, no. 1, pp. 119-125, 2001.

[26] P. R. Murray, E. J. Baron, M. A. Pfaller, F. C. Tenover, and R. H. Yolke, Manual of Clinical Microbiology, 1995, Washington, DC, USA.

[27] M. Ennouri, H. Fetoui, E. Bourret, N. Zeghal, and H. Attia, "Evaluation of some biological parameters of Opuntia ficus indica. 1. Influence of a seed oil supplemented diet on rats," Bioresource Technology, vol. 97, no. 12, pp. 1382-1386, 2006.

[28] Y. Habibi, L. Heux, M. Mahrouz, and M. R. Vignon, "Morphological and structural study of seed pericarp of Opuntia ficusindica prickly pear fruits," Carbohydrate Polymers, vol. 72, no. 1, pp. 102-112, 2008.

[29] M. Mouden, M. Boujnah, S. Salmaoui, S. Zantar, and A. Douira, "Effect of two extraction methods and harvest period and performance there statement of fatty oils of figs pear seed," International Journal of Pure \& Applied Bioscience, vol. 4, no. 1, pp. 1-8, 2016.

[30] A. El Finti, M. Belayadi, R. El Boullani, F. Msanda, and A. El Mousadik, "Assessment of some agro-technological parameters of cactus pear fruit (Opuntia ficus-indica Mill.) in Morocco cultivars," Journal of Medicinal Plants Research, no. 7, pp. 25742583, 2013.

[31] S. Majdi, M. Barzegar, A. Jabbari, and M. Agha Alikhani, "Supercritical fluid extraction of tobacco seed oil and its comparison with solvent extraction methods," Journal of Agricultural Science and Technology, vol. 14, no. 5, pp. 1043-1051, 2012.

[32] E. M. Marinova and N. V. Yanishlieva, "Antioxidative activity of extracts from selected species of the family Lamiaceae in sunflower oil," Food Chemistry, vol. 58, no. 3, pp. 245-248, 1997.

[33] Y.-Y. Soong and P. J. Barlow, "Antioxidant activity and phenolic content of selected fruit seeds," Food Chemistry, vol. 88, no. 3, pp. 411-417, 2004.

[34] J. R. Soares, T. C. P. Dinis, A. P. Cunha, and L. M. Almeida, "Antioxidant activities of some extracts of Thymus zygis," Free Radical Research, vol. 26, no. 5, pp. 469-478, 1997.
[35] İ. Gülçin, M. Oktay, E. Kireçci, and Ö. I. Küfrevioglu, "Screening of antioxidant and antimicrobial activities of anise (Pimpinella anisum L.) seed extracts," Food Chemistry, vol. 83, pp. 371-382, 2003.

[36] J. Lee, H. Chung, P.-S. Chang, and J. Lee, "Development of a method predicting the oxidative stability of edible oils using 2,2diphenyl-1-picrylhydrazyl (DPPH)," Food Chemistry, vol. 103, no. 2, pp. 662-669, 2007.

[37] A. Fazio, P. Plastina, J. Meijerink, R. F. Witkamp, and B. Gabriele, "Comparative analyses of seeds of wild fruits of Rubus and Sambucus species from Southern Italy: fatty acid composition of the oil, total phenolic content, antioxidant and anti-inflammatory properties of the methanolic extracts," Food Chemistry, vol. 140, no. 4, pp. 817-824, 2013.

[38] R. L. Prior, X. Wu, and K. Schaich, "Standardized methods for the determination of antioxidant capacity and phenolics in foods and dietary supplements," Journal of Agricultural and Food Chemistry, vol. 53, no. 10, pp. 4290-4302, 2005.

[39] A. Cardador-Martínez, C. Jiménez-Martínez, and G. Sandoval, "Revalorization of cactus pear (Opuntia spp.) wastes as a source of antioxidants," Ciencia e Tecnologia de Alimentos, vol. 31, no. 3, pp. 782-788, 2011.

[40] Z. Ghazi, M. Ramdani, M. Tahri et al., "Chemical composition and antioxidant activity of seeds oils and fruit juice," Journal of Materials and Environmental Science, vol. 6, no. 8, pp. 23382345, 2015.

[41] V. K. Bajpai, K.-H. Baek, and S. C. Kang, "Control of Salmonella in foods by using essential oils: a review," Food Research International, vol. 45, no. 2, pp. 722-734, 2012.

[42] K. Ziebell, R. P. Johnson, A. M. Kropinski et al., "Gene cluster conferring streptomycin, sulfonamide, and tetracycline resistance in Escherichia coli O157:H7 phage types 23, 45, and 67,' Applied and Environmental Microbiology, vol. 77, no. 5, pp. 1900-1903, 2011

[43] O. Chandra, K. J. Putra, and I. Wayan, "Antibiotic resistance profiles of Escherichia coli O157:H7 in cattle at Suth-Kuta, Badung Regency. Bali, Indonesia.," Global Veterinaria, vol. 15, no. 5, pp. 480-484, 2015.

[44] E. Moosazadeh, M. R. Akhgar, and A. Kariminik, "Chemical composition and antimicrobial activity of Opuntia stricta F. essential oil," Journal of Biodiversity and Environmental Sciences, vol. 4, pp. 94-101, 2014.

[45] S. Burt, "Essential oils: their antibacterial properties and potential applications in foods - a review," International Journal of Food Microbiology, vol. 94, no. 3, pp. 223-253, 2004.

[46] D. Mnayer, A.-S. Fabiano-Tixier, E. Petitcolas et al., "Chemical composition, antibacterial and antioxidant activities of six essentials oils from the Alliaceae family," Molecules, vol. 19, no. 12, pp. 20034-20053, 2014.

[47] A. O. Gill, P. Delaquis, P. Russo, and R. A. Holley, "Evaluation of antilisterial action of cilantro oil on vacuum packed ham," International Journal of Food Microbiology, vol. 73, no. 1, pp. 8392, 2002.

[48] M. Turgis, K. D. Vu, C. Dupont, and M. Lacroix, "Combined antimicrobial effect of essential oils and bacteriocins against foodborne pathogens and food spoilage bacteria," Food Research International, vol. 48, no. 2, pp. 696-702, 2012.

[49] H. Zengin and A. H. Baysal, "Antibacterial and antioxidant activity of essential oil terpenes against pathogenic and spoilage-forming bacteria and cell structure-activity relationships evaluated by SEM microscopy," Molecules, vol. 19, no. 11, pp. 17773-17798, 2014. 
[50] G. Tegos, F. R. Stermitz, O. Lomovskaya, and K. Lewis, "Multidrug pump inhibitors uncover remarkable activity of plant antimicrobials," Antimicrobial Agents and Chemotherapy, vol. 46, no. 10, pp. 3133-3141, 2002.

[51] M. Baltazar, A. Ngandjio, K. E. Holt et al., "Multidrug-resistant Salmonella enterica serotype typhi, Gulf of Guinea Region, Africa," Emerging Infectious Diseases, vol. 21, no. 4, pp. 655-659, 2015.

[52] J. Oumato, S. Zrira, M. Boujnah, and B. Saidi, "Effect of maturity stage on morphological and chemical characteristics of Opuntia ficus indica from Morocco," International Journal of Innovation and Applied Studies, vol. 20, no. 1, pp. 400-410, 2017.

[53] M. de Wit, A. Hugo, N. Shongwe, and R. van der Merwe, "Effect of cultivar, season and locality on lipid content and fatty acid composition of cactus pear seed oil," South African Journal of Plant and Soil, no. 33, pp. 279-288, 2016.

[54] Australian Oilseeds Federation Incorporated 2015 Section 1, "Quality standards, technical information \& typical analysis," no. 14, pp. 31-40, 2016, (Accessed 1 November 2015).

[55] A. Awad, A. Adel, A. A. M., Nady, and A.A.E., "Wheat germ: an overview on nutritional value, antioxidant potential and antibacterial characteristics," Food and Nutrition Sciences, vol. 6, no. 2, pp. 265-277, 2015.

[56] P. Pumrojana, S. Terapuntuwat, and P. Pakdee, "Influence of fatty acid composition of soybean oil vs. beef tallow on egg yolk fatty acid profiles of laying hens," Pakistan Journal of Nutrition, vol. 14, no. 7, pp. 383-387, 2015.

[57] A. F. Cerón, M. O. Osorio, and B. A. Hurtado, "Identificación de ácidos grasos contenidos en los aceites extraídos a partir de semillas de tres diferentes especies de frutas," Acta Agronómica, vol. 61, no. 2, pp. 126-132, 2012.

[58] J. Orsavova, L. Misurcova, J. Vavra Ambrozova, R. Vicha, and J. Mlcek, "Fatty acids composition of vegetable oils and its contribution to dietary energy intake and dependence of cardiovascular mortality on dietary intake of fatty acids," International Journal of Molecular Sciences, vol. 16, no. 6, pp. 1287112890, 2015.

[59] M. Derbali, A. Elaissi, I. Cheraief, and M. Aouni, "Fatty acid composition and antimicrobial activity against sensitive and multi-drug resistant bacteria of Tunisian Allium cepa seed extract," Research \& Reviews: Journal of Hospital and Clinical Pharmacy, vol. 2, no. 2, pp. 30-34, 2016.

[60] M. B. Suliman, A. H. Nour, M. M. Yusoff, P. Kuppusamy, A. R. Yuvaraj, and S. A. Mazza, "Fatty acid composition and antibacterial activity of Swietenia macrophylla king seed oil," African Journal of Plant Science, vol. 7, no. 7, pp. 300-303, 2013. 

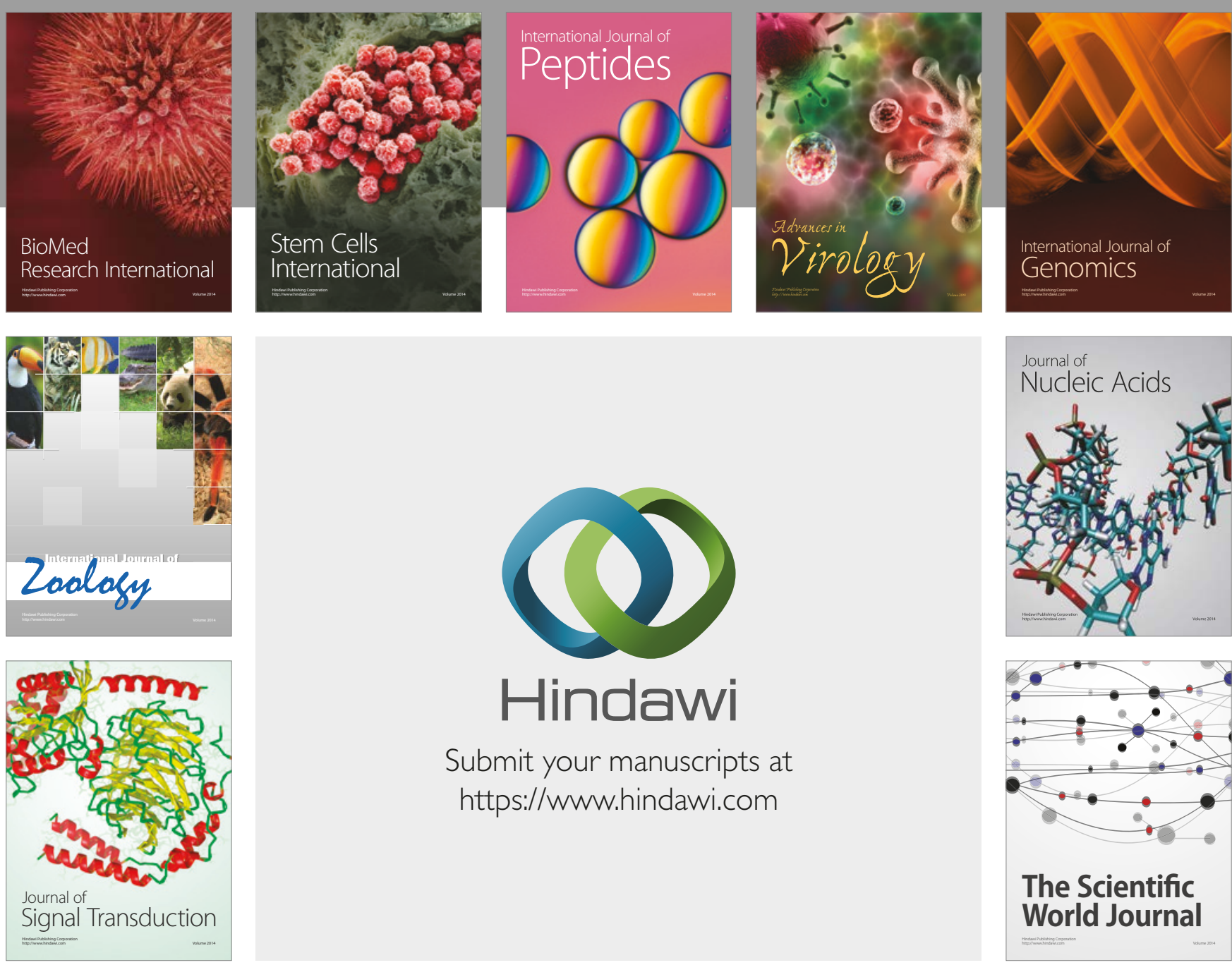

Submit your manuscripts at

https://www.hindawi.com
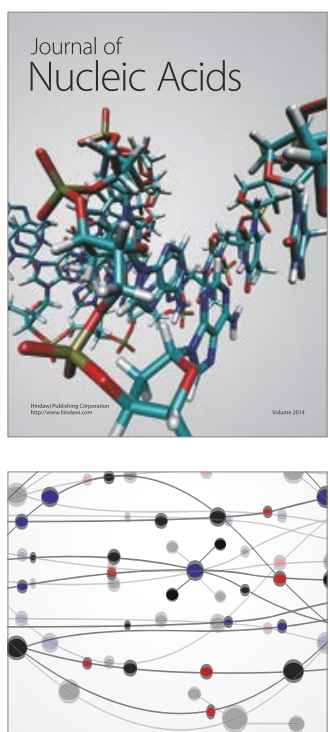

The Scientific World Journal

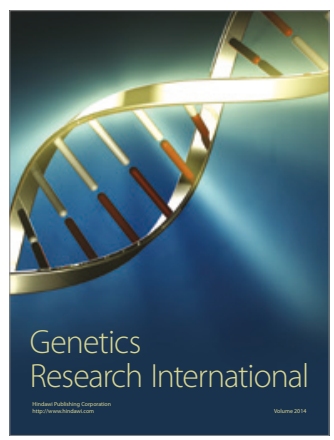

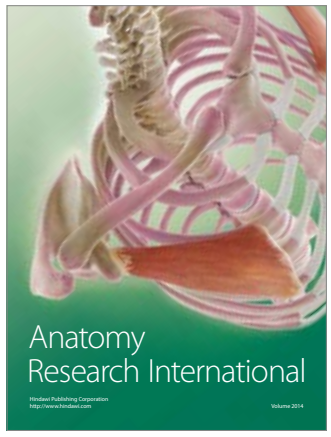

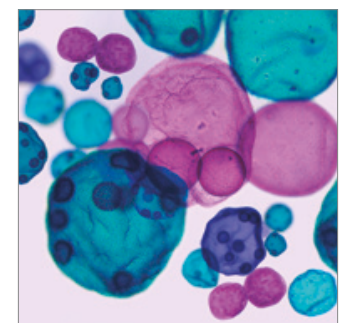

International Journal of Microbiology
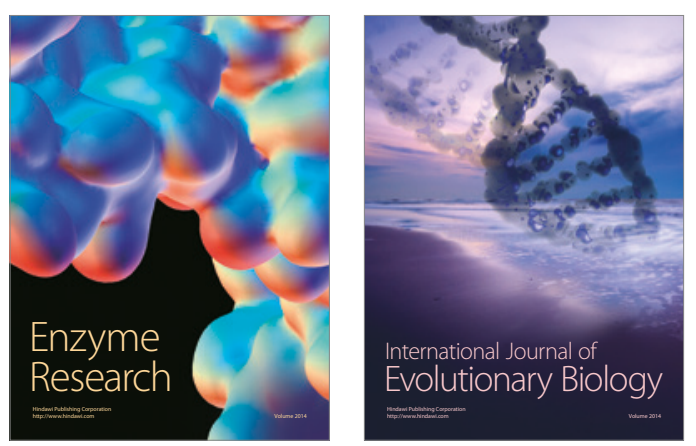
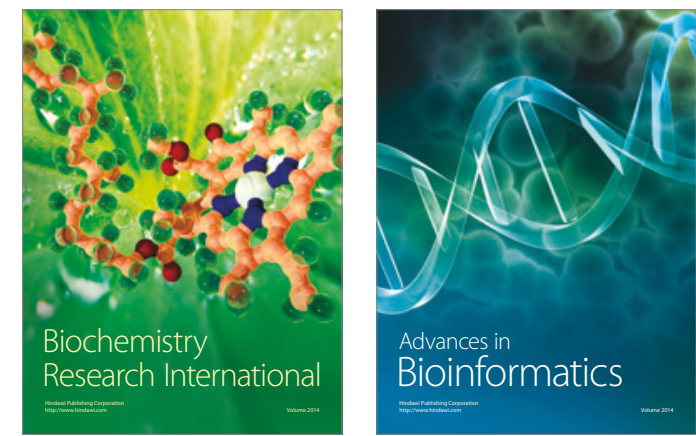

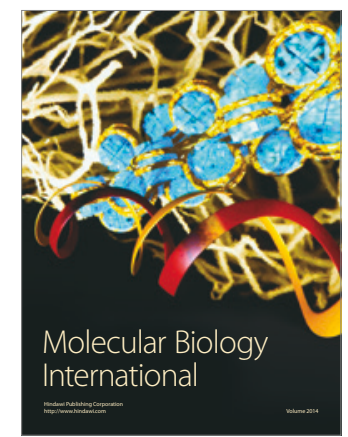

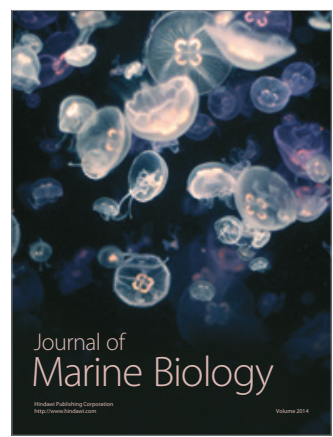

